\title{
Carbon Trading and India's Road Map
}

\author{
Dr. Debesh Bhowmik
}

\section{Retired principal and Former Associate Editor-Arthabeekshan-the journal of Bengal Economic Association}

\begin{abstract}
In this article, the author describes the concept of carbon trading, its global market, mechanism of global trading, international organization, EUETS, relationship between REDD and carbon market in relation with agreements of Paris convention. The 10 myths of REDD+ and carbon market are additional features which can explore future research. The paper highlighted India's roadmap for carbon market potentiality in 2020.
\end{abstract}

Keywords- Carbon trading, global carbon market, REDD, India's road map.

JEL-F18,O44,Q56

\section{WHAT IS CARBON TRADING}

Carbon trading is the buying and selling of a new, artificially-created commodity - the right to emit carbon dioxide. Unlike trading in other commodities like crude oil or bananas, carbon trading is not a voluntary exchange between producers and those who want to consume or sell on the goods. Instead, it results from action by governments to create this new commodity - the right to emit carbon and then to limit the availability of this right in order to create scarcity and therefore a market for it.

Carbon trading is one of a number of different approaches that have been developed and adopted by governments as a means of controlling the amount of carbon dioxide that is emitted into the atmosphere and reducing this amount over time. It is based on the broader approach, purportedly to control the emission of pollutants, known as 'cap and trade'. Cap and trade is often referred to as a market-based mechanism and contrasted with a different set of tools available to governments to influence behaviours, those which come under the umbrella of direct regulation or standard setting. However, this contrasting of market-based and non-market-based approach is sometimes unhelpful. It ignores the fact that market mechanisms do not operate in a vacuum. Instead, they always take place in a social and economic environment underpinned by various government laws and regulations and often require these laws in order to be effective. Carbon trading is a case in point. Carbon markets are directly created by government regulation.

Perhaps a more useful distinction for the purposes of this report is that between direct and indirect mechanisms. Carbon trading can be classed as an indirect tool as it is supposed to achieve its purpose of reducing emissions indirectly by affecting the price of those emissions. This in turn affects the behaviour of 'actors' in the market, i.e. those responsible for producing the emissions, by creating an incentive for them to save money by reducing their emissions and hence change their behaviour. In contrast, government regulation and standard setting are direct interventions to change behaviour, not reliant on intermediate mechanisms such as prices. Taxation is an indirect mechanism as it aims to change behaviour through affecting the price of a good, service or activity. However, it is arguably less indirect than trading as governments fix the price with a tax whereas with trading the price is determined by the market.

The carbon trade is an idea that came about in response to the Kyoto Protocol. The Kyoto Protocol is an agreement under which industrialized countries will reduce their greenhouse gas emissions between the years 2008 to 2012 to levels that are $5.2 \%$ lower than those of 1990 .

The idea behind carbon trading is quite similar to the trading of securities or commodities in a market place. Carbon would be given an economic value, allowing people, companies or nations to trade it. If a nation bought carbon, it would be buying the rights to burn it, and a nation selling carbon would be giving up its rights to burn it. The value of the carbon would be based on the ability of the country owning the carbon to store it or to prevent it from being released into the atmosphere. A market would be created to facilitate the buying and selling of the rights to emit greenhouse gases. The industrialized nations for which reducing emissions is a daunting task could buy the emission rights from another nation whose industries do not produce as much of these gases. The market for carbon is possible because the goal of the Kyoto Protocol is to reduce emissions as a collective.

On the one hand, the idea of carbon trade seems like a winwin situation: greenhouse gas emissions may be reduced while some countries reap economic benefit. On the other hand, critics of the idea suspect that some countries will exploit the trading system and the consequences will be negative. While the proposal of carbon trade does have its merits, debate over this type of market is inevitable since it 
involves finding a compromise between profit, equality and ecological concerns.

The carbon market is one of the most effective policies for tackling climate change. It inspires operational excellence and incentivizes business investments in low-carbon technologies. Not only is the market expected to save over 2 billion tones of $\mathrm{CO}_{2}$ emissions by the end of 2012, but the development of the current global carbon market, now worth over US $\$ 140$ billion, has catapulted climate change to the forefront of business decisions. But while it exhibits real environmental and economic impact, and helps achieve climate change goals, it remains vulnerable to external factors.

\section{GLOBAL CARBON TRADING}

Emission trading is considered an important market-based instrument to control emissions and is an essential element of the 1997 Kyoto Protocol. The EU Emissions Trading System (EU ETS) is the largest existing cap-and-trade system in the world and commenced operations in 2005. It covers about $2 \mathrm{Gt}$ of $\mathrm{CO}_{2}$ emissions at more than 10,000 installations across the $27 \mathrm{EU}$ member states. Following the EU ETS, an increasing number of world regions are currently introducing cap-and-trade systems that establish a price for greenhouse gas emissions. These include New Zealand, Australia, the Regional Greenhouse Gas Initiative (RGGI) of ten US-States in northeastern USA, California, the Western Climate Initiative (eight US-State and two Canadian Provinces), and the Midwestern Regional Greenhouse Gas Reduction Accord (nine US-States and one Canadian Province). In Japan, the cities of Tokyo and Hiroshima as well as the Kyoto prefecture intend to introduce mandatory emissions trading systems (Point Carbon, 2008). This development is underlined by the establishment of the International Carbon Action Partnership (ICAP) by several EU member states, the European Commission, California and other WCI members, several RGGI member states, New Zealand, and Japan (as an observer). ICAP sets up an expert forum to support the implementation and linking of emissions trading systems (ETS).

The Doha climate summit was no landmark event, but governments adopted an extension of the

Kyoto Protocol, set milestones in the lead up to a 2015 agreement. The most significant outcome from Doha was the adoption of the second commitment period of the Kyoto Protocol. Europe and a handful of others, amounting to less than $15 \%$ of global emissions, effectively put their existing national targets under the Kyoto framework. In doing so, they maintain the institutions and mechanisms established by the Protocol through to the end of 2020. However, only those developed countries which have taken on KP2 targets are eligible to use credits from Clean Development Mechanism (CDM) projects after 2012.

\section{INTERNATIONAL CARBON ACTION PARTNERSHIP}

The International Carbon Action Partnership (ICAP) constitutes an expert forum that explores design issues and linkages of regional emissions trading systems. ICAP investigates the relevant issues and proposes solutions where barriers are identified. The work of ICAP focuses on the three pillars of technical dialogue, ETS knowledge sharing and capacity building activities. ICAP's objectives are:

- Share best practices and learning from each other's experience of ETS

- Help policymakers recognize ETS design compatibility issues and opportunities for the establishment of an ETS at an early stage

- Facilitate future linking of trading programs

- Highlight the key role of emissions trading as an effective climate policy response

$\circ$ Build and strengthen partnerships amongst governments

The 'ICAP Political Declaration' (ICAP, 2007) states:

"The International Carbon Action Partnership (ICAP) will create an international forum of governments and public authorities that are engaged in the process of designing or implementing carbon markets. ICAP will establish an expert forum to discuss relevant questions on the design, compatibility and potential linkage of regional carbon markets. The forum will convene regularly and define a work program, including joint research and studies. It will identify barriers, including barriers posed by applicable state, federal and national laws, and it will identify solutions with the view to developing recommendations for consideration by each of the signatories hereto. ICAP aims to support the United Nations process on climate change by facilitating working relationships among governments and public authorities engaged in developing and implementing programs to combat climate change."

In particular, in the formal linking scenario ICAP could evolve to become the international clearinghouse for a carbon market established by linking domestic ETS.In order to deal with the uncertainty on the evolution of carbon markets and thus the future role of ICAP identifies critical design issues that are relevant in the global trading, formal linking, mixed approach and indirect linking scenario, respectively. 


\section{MECHANISM OF TRADING}

1. Global trading

A global emissions trading system building on the Kyoto approach can be established from the top-down as follows: an international treaty establishes national emission targets for all Annex-I (and possible other) countries for specified periods post-2012. From an economic point of view a global trading system is a first-best policy instrument that will ensure that the costs of achieving given reduction targets are minimized. Within this overarching framework, governments can devolve responsibility for allowance trading to the private sector by establishing domestic ETS and linking these to the domestic ETS of other regions. Thus governments will only have to

engage in international emissions trading on behalf of sectors that are not covered under a linked domestic ETS.

\section{Formal linking of domestic ETS}

If post-2012 negotiations within the UNFCCC do not lead to a global cap-and-trade consensus, nations and regions can establish domestic carbon markets and link these, thus constructing an international carbon market bottom-up (Tangen and Hasselknippe, 2005; Victor, 2007; Pizer, 2007). A major advantage of this approach is that if no agreement on a global trading system is achieved within UNFCCC negotiations by 2009, linking offers an opportunity to keep and build political momentum for constructing a global carbon market in the mid- to long term.

In principle, linking regional trading systems will enhance the efficiency of reduction efforts, increase liquidity of carbon markets, and reduce competitiveness concerns that could arise from different allowance price levels across systems (Edenhofer et al,2007). Unlike the global trading approach, however, the linking of regional trading systems does not allow controlling global emissions. Most of the issues arising when negotiating a global trading system remain important when linking bottom-up (e.g. defining a global policy target, and agreeing on burden sharing rules). However, these issues are negotiated only between the linking partners. Again, developing countries can participate in international emissions trading through credit schemes.

\section{Indirect linking}

Even if there is no agreement on formally linking regional emissions trading schemes, there will still be indirect linkages if national and regional domestic ETS accept credits from the same credit schemes like CDM. There will be some convergence in ETS price levels due to indirect linking. The levels of price convergence will depend on the supply curve of credits, import restrictions for credits, marginal abatements cost (MAC) curves and cap levels in the regional

ETS. However, this mechanism cannot guarantee that allowance prices across domestic ETS are completely equalized. More specifically, the degree of convergence of ETS allowance prices should be higher, the larger the available amount of credits and the less restrictive the limits for the import of credits into the ETS. In the indirect linking scenario all ETS that enable the use of a certain credit type need to agree on its design features. This particularly concerns monitoring and verification and the additional requirements that ensure emission reductions take solely place

due to the financing obtained from the credit scheme.

4. Mixed approach

Finally, mixed approach is conceivable containing elements of each of the stylized three approaches outlined above. If, for example, UNFCCC negotiations evolve towards agreement on a multilateral climate policy architecture by 2009 , but not all major emitters are willing to join a global cap-and-trade system immediately, the treaty may comprise a provision that enables reluctant countries or possibly subnational regions to join this scheme later. It is conceivable that the acceding regions would join the international trading system with their full economy or with some sectors only - that is, only their domestic ETS may be integrated into the global trading structure. It is also conceivable that developing countries gradually join such a trading system with specific sectors only, e.g. starting with the electricity sector.

\section{Clean Development Mechanism}

"Climate Change, Carbon markets and the CDM: A call to action" was released in September 2012. The report built the case for restoring faith in CDM, made 51 recommendations for addressing the shortcoming of CDM, improving performance and responding to future challenges and opportunities to keep it relevant to mitigation efforts. It urged nations to intervene to address the crisis in the carbon market and substantially increase level of mitigation ambition. However, the report did not result into any action at the UNFCCC conference in Doha in December 2012. The UNFCCC secretariat also launched The CDM Loan Scheme in 2012 to boost CDM project development in LDCs. The Scheme provides interest-free loans for CDM projects in LDCs as well as countries that have fewer than 10 registered CDM projects. The scheme is run jointly by the UNFCCC, the United Nations Environment Programme (UNEP) Risoe Centre and the United Nations Office for Project Services (UNOPS). The loans are utilized to finance 
the development of Project Design Documents (PDD), validation by a Designated Operational Entity (DOE), registration of the project with the UNFCCC and the monitoring and verification of Certified Emissions Reductions (CERs). In the first round of solicitation, the scheme received applications from 42 projects in 23 countries in Latin America and the Caribbean, Asia and Africa with the majority of the applications coming from Africa (29). Regional CDM support centres as well as loans for project developers in underrepresented regions also do not change the broader picture.

\section{REDD+ AND CARBON MARKET}

The world's forests are threatened by an ever-expanding demand for commodities such as soy, timber, palm oil and beef. Every year 13 million hectares of forests are being lost worldwide due to illegal or unsustainable logging and the conversion of forests to agricultural land. Emissions from forest degradation and deforestation account for $18 \%$ of

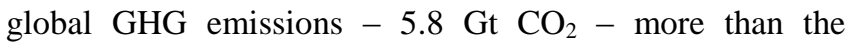
emissions of all EU countries combined. But forests are crucial in the struggle for sustainable development. Proposals to finance REDD+ reach from scaling up public finance, for example through the Green Climate Fund to including REDD+ activities in international carbon markets. A large number of developing countries continue to stress that forest-related activities under the UN Framework Convention on Climate Change (UNFCCC) must primarily be publicly funded. A little over ten years ago, forest conservation was excluded from the Clean Development Mechanism, and the EU decided to ban offset credits from forestry and land use land change activities (LULUCF) in the EU-ETS. There is an inherent high risk that forest offset credits do not represent real emission reductions due to leakage, the impermanence of forest carbon, inflated baselines, problematic additionality testing and difficult MRV. If these artificial credits would be traded in a global compliance market, global emissions would actually rise. However, offsetting is a zero sum game. Even if the credits would represent real emission reductions, allowing REDD projects in an offset mechanism would only shift emission reduction obligations from one country to the other and would not deliver the large long-term emission cuts required to stay below 2 degrees warming. Moreover, costs for the monitoring and implementation of forest carbon projects are high and fraudulent activities related to forest carbon trading have already been reported. REDD+ emission credits must therefore not be included in a global compliance market. Alternative financing options exist and should be prioritized. These include for example a fund- based approach, carbon taxes, levies on international aviation or maritime fuels and financial transaction taxes. A well designed REDD mechanism, in a larger mix of political instruments and financed outside of a compliance carbon market is an opportunity for the protection of forests and the biodiversity of forest ecosystems. However, forests play a vital part for biodiversity and forest-dependent communities around the globe. Therefore it is first and foremost essential that rights and livelihoods of forest dependent peoples are protected. Experience with afforestation and reforestation activities under the Clean Development Mechanism (CDM) has shown that impacts on forest peoples can be excessively negative. Displacements, land grabbing, restriction of traditional use of forests and other violations of indigenous peoples and forest dependent peoples have been reported. The same issues have been reported with voluntary forest carbon activities such as REDD pilot projects and forest conservation projects. A robust and harmonized safeguard framework must therefore be put in place to enable the protection of forest livelihoods, uphold human rights and the conservation of biodiversity. There must be systematical monitoring, reporting and verification of safeguards. Information about these processes to forest dependent peoples must be scaled up considerably.

\section{REDD+ AND CARBON MARKETS:TEN MYTHS EXPLODED}

Myth no. 1: 'REDD+ represents a low-cost abatement option, enabling greater and faster emissions cuts than could be achieved for the same total costs with fossil fuel reductions alone. This is essential for stabilizing GHG concentrations at the scale and speed necessary to avoid the most catastrophic effects of climate change.'

Myth no. 2: 'Estimates for the cost of cutting deforestation in half range from US $\$ 12$ billion to US $\$ 35$ billion per year. Raising this money will halve deforestation.'

Myth no. 3: 'Carbon trading finance can play an especially important role for REDD+ in the long term by contributing sustainable funding efficiently and on the scale required.'

Myth no. 4: 'Creating an economic value for standing forests will provide the necessary long-term economic incentives for effectively protecting tropical forests and reducing emissions from deforestation.'

Myth no. 5: "REDD+ is particularly well positioned to benefit from the policy shift from "project" to "sector wide" trading, given the suitability of forestry as a sector-wide mitigation effort.'

Myth no. 6: 'Significant work has already been undertaken on REDD+ methodologies to ensure quality by 
implementing rigorous measurement, reporting and verification requirements and determining reference levels which ensure additionality. As such, REDD+ is poised to be able to contribute rigorous, verifiable credits, fungible with emission reductions from other sources.'

Myth no. 7: 'Concerns about the potential risk of REDD+ supply "flooding" the carbon market can be contained through policy and market design, including the adoption of strict long-term targets with "banking" and, if necessary, limits on the use of REDD+ and other types of credits.'

Myth no. 8: 'For the period 2010-2012, developed countries committed US\$4.5 billion for REDD+. The gap between this figure and the estimated annual financing needs for REDD+ is significant.'

Myth no. 9: 'The US acid rain programme is an example of how cap-and-trade and market mechanisms can work to achieve environmental goals at least cost.'

Myth no. 10: 'Concerns about additionality, nonpermanence and leakage, which initially kept forests out of carbon markets, have been addressed.'

\section{PARIS CONVENTION, CARBON TRADING AND REDD}

Article 6 of the Paris Agreement states a new carbon trading mechanism. It manages to do so with mentioning the wind carbon or trading or market. Carbon offsets are internationally transferred mitigation outcomes. And the new carbon trading mechanism is a mechanism to contribute to the mitigation of GHG emissions and support sustainable development. On $8^{\text {th }}$ December,2015,Brazil and EU put forward a proposal on carbon market such as, "The EU and Brazil have agreed and submitted a ground breaking proposal on rules to governance of the international carbon market at the UN climate talks in Paris. The joint proposal demonstrates a willingness to engage in common and robust rules on accounting for all parties." The final rules of the new trading mechanism have not yet been agreed .It will only start in 2020 at the earliest. That means another five years of negotiating a new carbon market mechanism at the UNFCCC. Once the carbon trading mechanism kicks off, countries generating REDD credits will have no options.[i] Keep the REDD credit to offset the own emission from fossil fuels,[ii] Sell the REDD credits to countries that will use them to offset their emissions from fossil fuels.

Neither of these options reduces global GHG emissions, because in both cases the reduction in emission from forests would be offset against continued emissions from fossil fuels. Rich countries may finance REDD if it creates a loopholes allowing them to continue burning fossil fuels. But it is difficult to see why they would want to finance
REDD if it creates burning fossil fuels. At the start of COP21,Norway's PM Erna Solberg announced that Norway wants to include REDD in carbon markets, so that in future Norway can claim to be carbon neutral. We need to dramatically reduce emissions from burning fossil fuels and from deforestation. We can not afford to trade off one against the other. Unfortunately, the Paris Agreement sets the stage for precisely that.

\section{CARBON MARKET POTENTIAL FOR INDIA IN 2020}

Government of India embarked upon its National Action Plan on Climate Change (NAPCC) with 8 missions to ensure energy security, sustainable development, protection of bio-diversity and climate resilience in June 2008. These missions are:

i. National Solar Mission

ii. National Mission for Enhanced Energy Efficiency

iii. National Mission on Sustainable Habitat

iv. National Water Mission

v. National Mission for Sustaining the Himalayan Ecosystem

vi. National Mission for a "Green India"

vii. National Mission for Sustainable Agriculture and

viii. National Mission on Strategic Knowledge for Climate Change.

An expert group was constituted by the Planning Commission to develop a low carbon inclusive

growth strategy for India's Twelfth Five Year Plan. This Expert Group on Low Carbon Strategies for Inclusive Growth in its interim report estimated the national emissions reduction potential by 2020 for various sectors under two scenarios namely $8 \%$ and $9 \%$ annual GDP growth. The sectors covered are power sector, transport, iron \& steel, cement, oil \& gas, buildings, waste management, other industries and households. The Expert Group has either not considered or considered very limited potential in the following sectors: energy distribution, chemical industries, fugitive emissions from production and consumption of halocarbons and sulphur hexafluoride, construction, solvent use, mining/mineral production and fugitive emissions from fuels (solid, oil and gas). These sectors have been excluded from the analysis.

The regulatory framework, use of market mechanism and incentive mechanism (including price of emission reduction), will significantly influence carbon mitigation potential. This study examines the carbon market potential assuming CDM (or CDM like) framework in terms of baseline and crediting, additionality, etc. As the expert group has assumed a base year of 2007, the analysis has 
first linearly apportioned the estimate to make 2012 as the base year. Two adjustments to account for the characteristics of the CDM were also made to the Expert

Table.1: Estimated CDM potential in 2020 in million ton $\mathrm{CO}_{2}$

\begin{tabular}{|c|c|c|c|c|c|c|}
\hline Sectaral Scope & Activity & $\begin{array}{l}\text { Emission } \\
\text { ruduction } \\
\text { potential } \\
\text { (Mtco2) } \\
\text { estimated } \\
\text { by the Ex- } \\
\text { pert Eroup }\end{array}$ & $\begin{array}{l}\text { Maximum } \\
\text { emission } \\
\text { reduction } \\
\text { potential } \\
\text { (Mtco2) }\end{array}$ & $\begin{array}{l}\text { Enission } \\
\text { reduction } \\
\text { potential } \\
\text { (Mtco2) at } \\
\text { Euro 15) } \\
\text { (CO2e }\end{array}$ & $\begin{array}{l}\text { Emission } \\
\text { reductian } \\
\text { potential } \\
\text { (9tco2) } \\
\text { at Eure } \\
10 / \\
\text { tco2a }\end{array}$ & $\begin{array}{l}\text { Emission } \\
\text { reduction } \\
\text { potential } \\
\text { (MICO2) } \\
\text { at Eura } 5 \\
\text { tco2e }\end{array}$ \\
\hline \multirow{6}{*}{$\begin{array}{l}\text { Energy } \\
\text { industries } \\
\text { (enenewable - / } \\
\text { non-renewable } \\
\text { souroes) }\end{array}$} & Solar & 16 & 11.72 & 000 & 0.00 & 000 \\
\hline & Biomass: & 12 & 5.82 & 5.82 & 490 & 000 \\
\hline & Wind & 11 & 831 & 831 & 791 & 000 \\
\hline & $\begin{array}{l}\text { Foscil fuel switoh (6as } \\
\text { Baced Combined cycle) }\end{array}$ & 8. & 509 & 509 & 4.67 & 328 \\
\hline & $\begin{array}{l}\text { Supereritical oosl power } \\
\text { plants }\end{array}$ & 5 & 0.28 & 0.28 & 028 & 000 \\
\hline & Hydro & 28 & 424 & 0.16 & 0.00 & 000 \\
\hline \multirow[t]{3}{*}{$\begin{array}{l}\text { Energy de- } \\
\text { mand }\end{array}$} & $\begin{array}{l}\text { EE commercial building } \\
\text { IHeating, Ventilation and } \\
\text { Air conditioning, Lighting. } \\
\text { Interoal Loads and others] }\end{array}$ & 37 & 023. & 023 & 023 & 023 \\
\hline & Lighting & 27 & 26.20 & 26.20 & $26: 20$ & 000 \\
\hline & Fan TV and $A C$ & 12 & 246 & 2.46 & 246 & 246 \\
\hline \multirow[t]{3}{*}{$\begin{array}{l}\text { Manufacturing } \\
\text { industries }\end{array}$} & $\begin{array}{l}\text { Energy Efhciency - Clinker } \\
\text { Substitution in Coment" }\end{array}$ & 31 & 000 & 000 & 000 & 000 \\
\hline & $\begin{array}{l}\text { Energy Efficiency - Fuel } \\
\text { Substitution in Cement }\end{array}$ & 5 & 243 & 2.43 & 243 & 005 \\
\hline & Refrigerators & 4 & 0.74 & 0.74 & 0.74 & 0.74 \\
\hline \multirow[t]{3}{*}{$\begin{array}{l}\text { Metal produc- } \\
\text { tien }\end{array}$} & $\begin{array}{l}\text { BF-BOF including waste } \\
\text { heat projects }\end{array}$ & 17 & 11.08 & 11.08 & 11.08 & 11.08 \\
\hline & COREX/FNEX-BOF & 3 & 1.56 & 1.56 & 1.56 & 156 \\
\hline & ORI-EAF and F-Technology & 2 & 123 & $1: 23$ & 1.23 & 123 \\
\hline \multirow[t]{2}{*}{ Traneport } & $\begin{array}{l}\text { Modal shift - Inereased } \\
\text { freight share of Raitways } \\
\text { and Nen-mutorised and } \\
\text { publie transport }\end{array}$ & 19 & 139 & 139 & 139 & 1.17 \\
\hline & Fuel efficiency of vehicles & 7 & 0.60 & 0.60 & 0.60 & 0.60 \\
\hline \multirow{2}{*}{$\begin{array}{l}\text { Wocte has- } \\
\text { dling and } \\
\text { disposeal }\end{array}$} & $\begin{array}{l}\text { Landfill gas - (Composting, } \\
\text { Solid waste, manure) }\end{array}$ & 37 & 1270 & 1270 & 1270 & 174 \\
\hline & Wastewater & & & & & \\
\hline $\begin{array}{l}\text { Afforestation } \\
\text { and reforesta- } \\
\text { tion }\end{array}$ & Reforestation/Afforestation & 28 & 0.37 & 012 & 0.00 & 000 \\
\hline Agriculture & Agricultute & 3 & 308 & 000 & 0,00 & 000 \\
\hline \multicolumn{2}{|l|}{ Total } & 307 & 995 & 8038 & 7835 & 2411 \\
\hline
\end{tabular}

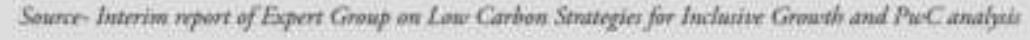

As part of voluntary commitments, India has pledged reducing its emissions intensity of its GDP by $20-25 \%$ by 2020 in comparison to the 2005 level. Though restrictions around technologies (HFC23 and $\mathrm{N} 2 \mathrm{O}$ abatement in adipic acid production) post true up period has no detrimental impact on the Indian supplies, yet the absence of demand for Indian projects registered after 31 December 2012 has
Group's analysis to quantify the Indian CDM potential in 2020 (Table 1): resulted in reduced investment in several other sectors.Figure -1 shows the total investment into CDM projects for each state in the country. Industrialized states also have high renewable energy potential and this has lead to concentration of investments in the states of Gujarat, Andhra Pradesh, Maharashtra, Tamil Nadu and Karnataka. Himachal Pradesh has benefited from large number of 
hydro CDM projects, which is to be expected given its hydro potential, and Delhi because of transport CDM projects. High investment in Madhya Pradesh in on account of coal based supercritical power projects. Arunachal Pradesh, Assam, Bihar, Kerala and West Bengal have seen very limited investments into CDM. Biomass CDM projects in the sample are the most efficient job creator and create more than four times the average jobs (per rupee invested) across all project-types. Wind and hydro projects in the sample create relatively less employment per rupee invested as compared to EE own generation and EE industry projects during the construction phase.

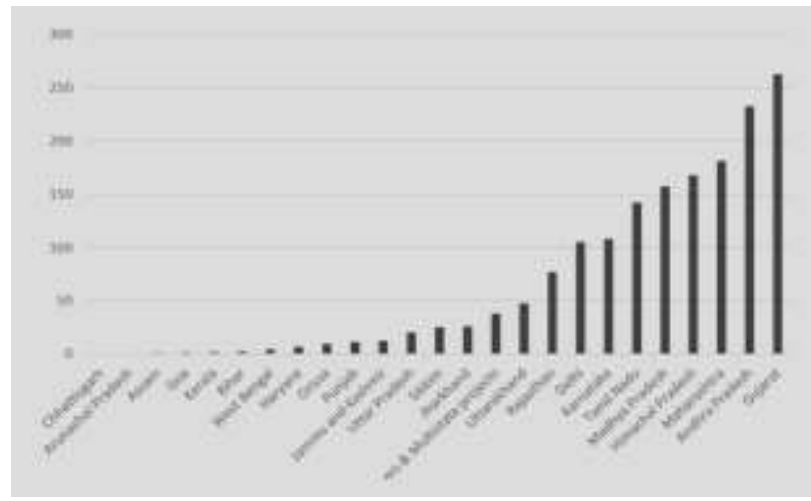

Fig.1:Statewise investment in CDM projects (Rs billion)

Source: BMUB Global Carbon Market Project, New Delhi

The Harnessing demand for Indian projects post-2012 are :

1. Supporting projects through domestic emission trading scheme -

2. Supporting projects through NCEF and CSR funds of large companies

3. Developing standardized baselines

4. Developing sustainable development impact reporting

5. 5.Evaluating and highlighting the benefits of CDM projects focusing on sustainable development Impacts

6. 6. Constituting a high level Multi Stakeholder Advisory Group for Climate Change issues

7. like Loss and Damage, Equity, Sustainable Development, Gender etc

8. 7. Developing NAMAs

9. 8. Developing the capacity for national emission reduction reporting and develop credible and robust reporting frameworks for corporate carbon reporting-

But there are several causes of delays of maturing projects which are as follows: i. One of the major reasons for delays in registration of CDM projects is on account of lack of acceptable guidelines for setting benchmark, lack of institutional capacity, frequent revisions to CDM EB guidelines and lengthy validation cycle

ii. The delay in registration of CDM projects was due to the increase in CDM projects from India and limited increase in the number of DOEs

iii. The cement and energy efficiency project-types have higher rejection rate than hydro and wind projecttypes

iv. Projects in reforestation, EE household, EE in SME, off-grid solar and agriculture project-types face $M R V$, organizational and financial barriers.

v. HFC 23, N2O and landfill gas(where these is no energy generation) projects risk closure post the withdrawal of market support and fall in CER prices

vi. Goa, Bihar, Jharkhand, Kerala, Jammu \& Kashmir, Haryana and North Eastern states have very limited development of CDM projects

The promotion and development of the emission reduction projects will require a combination of the following measures:

i. Demand-side measures: Given the weak demand for CERs and the uncertain time frame for new market mechanisms, all attempts should be made to revive demand in the existing regulatory framework, particularly for projects registered post 2012.

ii. Improving sustainable development impacts: Improving the sustainable development impacts as well as improving communication on the outcomes / impacts of CDM project activities is required for stimulating demand of quality CDM projects and addressing international concerns.

iii. Efficiency of registration: Once there is a revival of demand, measures should be undertaken to remove the barriers in CDM project registration while also improving sustainable development impacts.

iv. Future regulatory mechanisms: Recognizing that CDM is likely to be transitory in nature and new market mechanisms are likely to be more prominent particularly in the post 2020 carbon markets, measures should be undertaken to develop synergies between CDM, NAMAs and other market mechanisms.

v. Supply side measures: Once there is regulatory certainty and robust demand, supply side measures should be undertaken that encourage larger participation of industry in emerging global carbon / CDM market. 
Therefore, the recommendations below are targeted towards:

A. Harnessing demand for Indian projects post 2012;

B. Achieving better sustainable development for CDM projects;

C. Developing synergies between CDM, NAMAs and other market mechanisms; and

D. Encouraging larger participation of industry in carbon market.

\section{CONCLUDING REMARKS}

The international carbon market currently faces considerable uncertainties regarding its future architecture. There are a number of options for further development, including a global trading approach building on Kyoto, formal linkages of domestic ETS leading to a global CO2 market, and indirect linkages through credits if domestic ETS remain otherwise unconnected. Also, a mixed approach is conceivable. Regions should share a common understanding on the overall

climate policy goal (e.g., the $2^{\circ} \mathrm{C}$ target) as well as a burden-sharing rule translating into ETS caps. These two fundamental issues will crucially determine the level of ambition of an ETS as expressed in (a) the emission cap, which in combination with amount and costs of available abatement options of a region crucially determines the allowance price level; and (b) ETS design features also exerting influence on the allowance price level and environmental outcome. For a player with ambitious environmental targets it should be preferable to announce that it will link only under the condition that another system displays a similar level of ambition, thus using the efficiency and potential reputational benefits from linking as a bargaining chip. Linking to less ambitious regions would undermine the credibility of such announcements. Harmonization of trading systems should start as early as possible in order to enable the option of linking ETS post2012. For this purpose, ICAP could be a nucleus for such an international clearinghouse.

\section{REFERENCES}

[1] Angelsen, Arid., Gierloff, Caroline Wang ,Beltran, Angelica Mendoza \& Elzen, Michel den . (2014). REDD Credits in a global carbon market: Options and Impacts. NORDEN.

[2] Anger, N., Dixon, A \& Livengood, E.(2009). Interactions of Reduced Deforestation and the Carbon Market. The Role of Market Regulations and Future Commitments. Center for European Economic Research: Discussion Paper No. 09-001.
[3] Baron, R.\& Bygrave, S.(2002). Towards International Emissions Trading: Design implications for linkages. IEA/OECD Paper.

[4] Bhowmik, Debesh. (2017).An Introduction to Climate Change, Synergy Books India Ltd, New Delhi.

[5] Deutsche Gesellschaft fur Internationale Zusammenarbeit.(2014,January).Carbon Market Road Map for India, BMUB Global Carbon Market Project, New Delhi.

[6] Edenhofer, Ottmar, Flachsland, Christian \& Marschinski,Robert.(2007,May). Towards a global $\mathrm{CO}_{2}$ market. Expertise for the Policy Planning Staff in the Federal Foreign Office. Potsdam Institute for Climate Impact Research.

[7] Ellermann, Denny.(2012). Linking Emissions Trading Schemes: Back to the Basics; paper presented on 12 November 2012 at the ZEW Conference "Rise of ETS in Asia"

[8] Ellis, J. \& Tirpak, D.(2006). Linking GHG Emission Trading Systems and Markets. IEA/OECD Paper.

[9] German Emission Trading Authority.(2013).Linking Different Emissions Trading System: Current State and Future Perspectives, Berlin.

[10] Hausotter, Tobias.,Sibyl, Steuer \& Dennis, Tanzler.( 2011). Competitiveness and Linking of Emission Trading Systems (UBA Climate Change 01/2011) http://www.umweltdaten.de/publikationen/fpdf1/4051.pdf

[11] Karsenty,A.(2009). 'What the (carbon) market cannot do.' CIRARD. http:/www.cirad.fr/en/news/all-newsitems/articles/2009/just-out/perspective

[12] Moyes, T.E.(2008). Greenhouse gas emission trading in New Zealand: Trailblazing comprehensive cap and trade. Ecology L.Q. 911

[13] Murray, B. C., Lubowski,R \& Sohngen,B. (2009). Including International Forest Carbon Incentives in Climate Policy: Understanding the Economics. Nicholas Institute Report. Durham, NC: Nicholas Institute for Environmental Policy Solutions, Duke University.

[14]Pirard, R.(2008). 'The fight against deforestation (REDD+): economic implications of market-based funding.' Paris: IDDRI.

[15]Pizer, William.(2007). Practical Global Climate Policy. In: Aldy, Joseph E., and Robert N. Stavins (2007): Architectures for Agreement. Addressing Global Climate Change in the Post-Kyoto World. Cambridge University Press 
[16]Potsdam Institute for Climate Impact Research.(2008).Developing the International Carbon Market: Linking Options for EUETS,NZ

[17] Tangen, Kristian \& Hasselknippe, Henrik. (2005, March).Converging Markets. International Environmental Agreements: Politics, Law and Economics. Volume 5, No 1.

[18] The Carbon Trust. (2008). Global Carbon Mechanisms: emerging lessons and implications. UK: Carbon Trust, p. 11.

[19] The Munden Project. (2011).REDD+ and forest carbon. $\quad$ http://www.mundenproject.com/ forestcarbonreport2.pdf

[20] The RAIN FOREST FOUNDATION. (2011, June). REDD+ and Carbon Market:10 Myths exploded, Green peace.

[21] UNEP. (2010). Bringing forest carbon projects to the market, New York.

[22] UNFCCC. (2010b). Quantified economy-wide emission targets for 2020- Appendix I. Available from http://unfccc.int/home/items/5264.php

[23] Victor, David.(2007). Fragmented carbon markets and reluctant nations: implications for the design of effective architectures. In: Aldy, Joseph E., and Robert N. Stavins (2007): Architectures for Agreement. Addressing Global Climate Change in the Post-Kyoto World. Cambridge University Press

[24] World Bank. (2011,June). State and Trends of the Carbon Market 2011. Carbon Finance at the World Bank, Washington DC.

[25]Zetterberg, Lars. ( 2012). Linking the Emissions Trading Systems in EU and California, Fores, Stockholm http://fores.se/assets/780/FORESCalifornia_ETS-web.pdf 